\title{
Determination of the Antiangiogenic Activity of Telescopium telescopium (Horn snail) Extract using in ovo Chorioallantoic Membrane (CAM) Assay
}

\author{
Milany Anne M. Luay, ${ }^{1}$ Mary France R. Gonzaga, ${ }^{1,2}$ Sharmaine Kae D. Po ${ }^{1}$ and Erna C. Arollado ${ }^{1,2}$ \\ ${ }^{1}$ Department of Pharmacy, College of Pharmacy, University of the Philippines Manila, \\ ${ }^{2}$ Institute of Pharmaceutical Sciences, National Institutes of Health, University of the Philippines Manila
}

\begin{abstract}
Objective. To determine the antiangiogenic activity of Telescopium telescopium (Horn snail) extract using in ovo chorioallantoic membrane (CAM) assay.

Methods. Methanolic extract of Telescopium telescopium was subjected to modified Kupchan partitioning. Four treatment groups - negative control, positive control (quercetin), test samples, and blanks - were used for the in ovo chorioallantoic membrane (CAM) assay. ImageJ software was used to measure average vessel diameter (DV) and total length (LT) to determine the degree of vascularization, percent inhibition, and antiangiogenic activity. Biochemical screening was done for the crude extract and the fraction with the highest percent inhibition.

Results. Butanol fraction showed the highest percent inhibition in both average vessel diameter $\left(D_{\vee}\right)(417.30 \% \pm$ $300.83)$ and total length $\left(L_{T}\right)(44.21 \% \pm 8.11)$. There was no significant difference in the antiangiogenic activity of both crude and butanol fraction compared with quercetin. Biochemical screening confirmed the presence of sterols and carbohydrates in both fractions.
\end{abstract}

Conclusion. Crude extract and butanol fraction resulted in positive percent inhibition values, indicating inhibition of angiogenesis. They were found to have no significant difference with quercetin in regard to their antiangiogenic activity. Sterols were assumed as the biochemical class of the antiangiogenic compound of interest.

Key Words: antiangiogenic, anticancer, chorioallantoic membrane assay, mollusk, Telescopium telescopium

\section{INTRODUCTION}

Corresponding author: Milany Anne M. Luay

Department of Pharmacy, College of Pharmacy,

University of the Philippines Manila

Pedro Gil Street, Taft Avenue, Ermita, Manila, 1000

Metro Manila Philippines

Telephone: +639164596095

E-mail:mmluay@up.edu.ph
According to the World Health Organization, cancer accounts for about $10 \%$ of the total deaths caused by noncommunicable diseases. In the Philippines, approximately 59,000 people die of cancer and this causes alarm since the number of affected individuals keeps on increasing annually. ${ }^{1}$

Malignant tumor (cancer) progression involves angiogenesis which is the formation of new blood vessels. ${ }^{2}$ Recent studies have focused on finding factors that induce or inhibit this reaction. ${ }^{3}$ Attention has been focused on the discovery of mechanisms and mediators responsible for the timely down-regulation of angiogenesis. ${ }^{4}$

The marine ecosystem is recognized as an important source of bioactive compounds having medicinal potential. About 2\% of the major sources of biomedical compounds obtained from invertebrates come from the phylum Mollusca. The mollusks, one of the most abundant marine 
species, have actually yielded notable anticancer compounds such as dolastatin, acharan sulphate, kahalalide F, and kulolide. ${ }^{5}$ Some of these compounds are in the clinical trial phase like elisidepsin that showed preliminary evidence of antitumor activity. ${ }^{6}$ More than 2,600 scientific studies have been carried out over the past 20 years on the different species of this phylum. ${ }^{7}$

Telescopium telescopium (Horn snail), from the family Potamididae of phylum Mollusca known as bagongon in Filipino, has been found to have different pharmacological actions. This snail, usually sold in traditional markets and used in local cuisines, has a great potential in developing immunomodulators and antitumor agents. Restriction of the tumor growth by Telescopium telescopium maybe due to the antiangiogenic activity of the compound rather than direct tumor cell killing ability. ${ }^{5}$ Thus, this study was undertaken to determine the antiangiogenic activity of Telescopium telescopium soft bodies using in ovo chorioallantoic membrane (CAM) assay.

\section{MATERIALS AND METHODS}

\section{Identification, collection, and extraction procedure}

Seven kilograms of live Telescopium telescopium were collected from the province of Iloilo in Visayas and authenticated by the National Museum of the Philippines. Outer shells were cut open to separate the soft bodies, which were then chopped into small pieces, about $1 \mathrm{~cm}$ in length and width. Four kilograms of soft bodies were macerated with 2.5 liters of methanol for seven days. The extract was then filtered and concentrated using a rotary evaporator at no more than $35^{\circ} \mathrm{C}$ to avoid degradation of compounds. This extraction procedure was conducted in the Plant Chemistry Laboratory at the College of Pharmacy, University of the Philippines Manila.

\section{Bioassay-guided fractionation}

The methanol extract was suspended in distilled water, and then extracted three times, with dichloromethane, giving aqueous and organic layers. The aqueous layer was partitioned with butanol for further separation. For the organic layer, the dichloromethane solvent was evaporated. The resulting extract was suspended in methanol:water (9:1) mixture, then extracted with hexane. After separation, the methanol:water (9:1) mixture was adjusted to 50/50 and the resulting mixture was extracted with dichloromethane.

Likewise, the solvent fractions were further subjected to a water bath to evaporate the solvents. The yields of each of the fractions were also computed.

\section{Preparation of test samples and test organisms}

The methanol extract, as well as different fractions, were dissolved in their corresponding solvents which yielded a concentration of $10 \mathrm{mg} / \mathrm{mL}$ for the preparation of discs; $10 \mu \mathrm{L}$ of each of the solutions were applied dropwise using a $20 \mu \mathrm{L}$ capillary pipette on a sterile filter paper disc of 3 $\mathrm{mm}$ diameter, and were dried under laminar airflow, giving a concentration of $100 \mu \mathrm{g}$ per disc.

Five-day old fertilized duck eggs were collected from a local balut (duck egg with developing embryo) producer in Inaoan, Pulilan, Bulacan. Dirt, feathers, and excrement were carefully removed from the eggshells mechanically by dry wiping with paper towels. The incubation temperature was set at $37.8^{\circ} \mathrm{C}$ with a humidity of $47 \%$. The test organisms were handled in accordance to good animal practice and as approved by the Institutional Animal Care and Use Committee (IACUC), University of the Philippines Manila.

\section{Duck embryo in ovo chorioallantoic membrane (CAM) assay}

The test organisms were divided into four different treatment groups - groups for the positive control, negative control, blank, and test samples, all done in triplicates. The groups, except for the negative control, contained substanceinfused discs applied on the ducks' CAM. The treatment groups are shown in Table 1.

Table 1. Treatment groups and their corresponding disc solutions Treatment Group Disc Solution

Positive control

$100 \mu \mathrm{g}$ quercetin

Negative control

Blank (solvent control)

No substance added

$10 \mu \mathrm{L}$ methanol

$10 \mu \mathrm{L}$ distilled water

$10 \mu \mathrm{L}$ n-butanol

$10 \mu \mathrm{L}$ methanol:water (50/50)

$10 \mu \mathrm{L}$ dichloromethane

$10 \mu \mathrm{L}$ hexane

Test sample

$10 \mu \mathrm{L}$ of $10 \mathrm{mg} / \mathrm{mL}$ crude methanolic extract
$10 \mu \mathrm{L}$ of $10 \mathrm{mg} / \mathrm{mL}$ aqueous fraction
$10 \mu \mathrm{L}$ of $10 \mathrm{mg} / \mathrm{mL}$ butanol fraction
$10 \mu \mathrm{L}$ of $10 \mathrm{mg} / \mathrm{mL}$ methanol:water fraction
$10 \mu \mathrm{L}$ of $10 \mathrm{mg} / \mathrm{mL}$ dichloromethane fraction
$10 \mu \mathrm{L}$ of $10 \mathrm{mg} / \mathrm{mL}$ hexane fraction

After one day of acclimatization in the incubator, the eggs were cracked open under laminar airflow. To further minimize contamination, sterile hand gloves were used ${ }^{8}$

A small window was made on the shell of the six-day old egg. Unfertilized eggs or dead embryos characterized by a non-pulsating heart, yolk leakage, or interrupted aspect of the blood vessels were discarded. ${ }^{8}$ The CAMs, with the eggs placed on a tray, were then photographed using a digital single-lens reflex camera (Canon EOS 500D) for the pre-test observation. Substance-infused discs were placed over the area near the plexus, the most visible blood vessel. The window was resealed with an adhesive wrap to prevent dehydration of the egg and to protect them from contamination from dust and dirt. In ovo cultures 
were returned to the incubator, where temperature was maintained at $37.8{ }^{\circ} \mathrm{C}$ and humidity at $47 \%$. The post-test observation was done a day after.

After removing the paper filter discs, the CAMs were photographed using the same DSLR camera (Canon EOS 500D) for the post-test observation. The embryos were then sealed and buried in a compost pit.

\section{Biochemical screening}

For qualitative analysis, the crude methanolic extract and the fraction of the highest percent inhibition were subjected to biochemical screening. The extracts were screened for carbohydrates, proteins, sterols, and alkaloids.

\section{Duck embryo in ovo chorioallantoic membrane (CAM) assay analysis}

The degree of vascularization in the treatment groups was measured as the percent growth of the vascular networks and was computed using Equation 1. The values of both $\mathrm{P}$ and $\mathrm{P}_{\mathrm{o}}$ were generated using ImageJ, a computer software used for scientific image analysis. ImageJ measures several morphological and spatial parameters including the average vessel diameter $\left(D_{V}\right)$. On the other hand, the Angiogenesis Analyzer, a toolset for Image that allows the analysis of cellular networks, was used to measure the total length $\left(\mathrm{L}_{\mathrm{T}}\right)$.

Through ImageJ, morphometric analysis was done for the quantification of antiangiogenic activity of the Telescopium telescopium (horn snail) extracts; average vessel diameter $\left(\mathrm{D}_{\mathrm{V}}\right)$ and total length $\left(\mathrm{L}_{\mathrm{T}}\right)$ were two parameters used for the computation of percent growth.

Total length $\left(\mathrm{L}_{\mathrm{T}}\right)$, in pixels, is the sum of length segments, isolated elements, and branches in the analyzed area. On the other hand, average vessel diameter $\left(D_{V}\right)$ is the estimated typical value of the width of the vessels in an image. It was derived from the vessel length density and vessel area density

$$
\text { Percent growth }=\frac{P-P_{0}}{P} \times 100
$$

Where $\mathrm{P}=$ vascular parameter of the treated CAM

$\mathrm{P}_{0}=$ vascular parameter of the untreated CAM

Equation 1. Computation for the percent growth of vascular network. as shown in Equation 2. Vessel length density $\left(\rho_{\mathrm{L}},[\mathrm{mm} /\right.$ $\left.\mathrm{mm}^{2}\right]$ ) is the number of pixels that belong to the skeletonized network divided by the total area of the image. Vessel area density $\left(\rho_{\mathrm{A}},\left[\mathrm{mm} / \mathrm{mm}^{2}\right]\right)$, on the other hand, is the number of pixels that belong to the vascular network divided by the total area of the image.

The percent inhibition was computed using Equation 3. Positive percent inhibition indicates a decrease in vascularization, thus the inhibition of vascularization; negative percent inhibition indicates an increase in vascularization, thus the absence of inhibition of vascularization. Equation 4 was used to account for the blank solutions used in the test samples.

\section{Statistical analysis}

The percent inhibitions of the different treatment groups were determined and expressed as mean \pm SEM. After establishing that the data collected were normally distributed and homogenous, one-way analysis of variance for complete randomized design (ANOVA-CRD) followed by Dunnett's post hoc test with equal replications was used to determine the significant differences between the positive control and the treatment groups. ${ }^{9}$ As for the significant difference between the crude and the fraction of the highest percent inhibition, Tukey's honest significant difference (HSD) post hoc test was used as it is the procedure of choice in the comparing paired means. ${ }^{10}$ Stata/MP-Parallel Edition 13.0 was used for all the statistical analysis of the study.

\section{Biochemical screening analysis}

The determination of the possible biochemical compounds present in Telescopium telescopium was done using different biochemical tests. The biochemical screening of the extracts tested for carbohydrates, proteins, sterols, and alkaloids.

$$
D_{V}=\frac{\rho_{A}}{\rho_{L}} \times 100
$$

Where $\rho_{A}=$ vessel area density

$\rho_{\mathrm{L}}=$ vessel length density

$D_{V}=$ average vessel diameter

Equation 2. Computation of average vessel diameter.

$$
\text { Percent inhibition }=\frac{\text { Percent growth in control }- \text { Percent growth in treatment }}{\text { Percent growth in control }} \times 100
$$

Equation 3. Computation for the percent inhibition.

Percent inhibition $_{\text {(adjusted for blank) }}=$ Percent inhibition $_{\text {test sample }}-$ Percent inhibition $_{\text {blank }}$

Equation 4. Computation for the adjusted percent inhibition. 


\section{RESULTS}

\section{Extraction and bioassay-guided fractionation}

Five fractionates were obtained after modified Kupchan partitioning which yielded 5.0453 gram methanolic extract as shown in Table 2.

Table 2. Yield of solvent fractions from modified Kupchan partitioning

\begin{tabular}{lcc}
\multicolumn{1}{c}{ Solvent fraction } & Actual yield (g) & Percent yield (\%) \\
\hline Aqueous & 3.038 & 60.214 \\
Methanol-Water & 0.149 & 2.953 \\
Butanol & 1.381 & 27.372 \\
Dichloromethane & 0.267 & 5.292 \\
Hexane & 0.138 & 2.735 \\
\hline
\end{tabular}

\section{Duck embryo in ovo chorioallantoic membrane (CAM) assay}

Out of 70 eggs used in the study, only 59 (84.29\%) were viable and $11(15.71 \%)$ were non-viable. The remaining viable eggs were divided into the different treatment groups, with
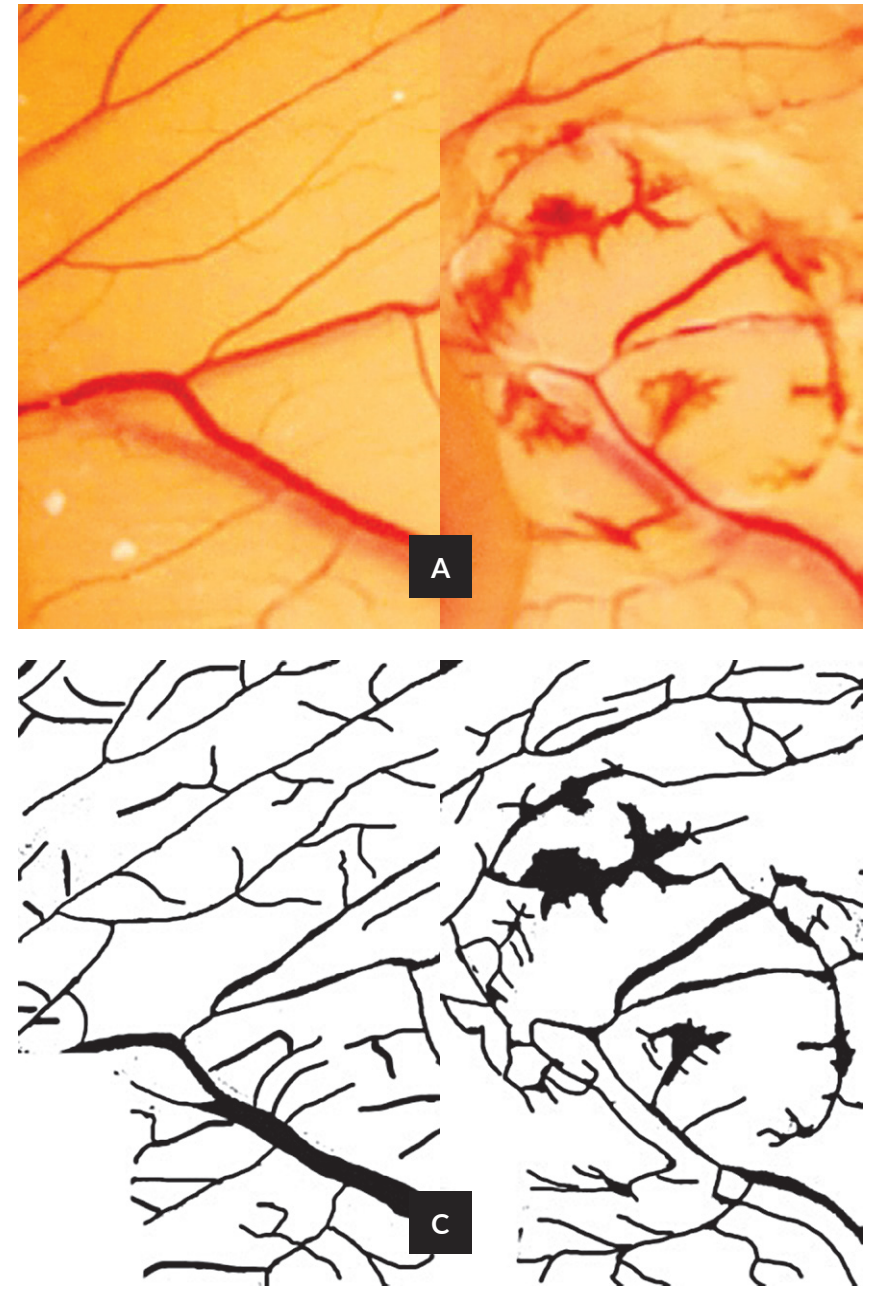

one additional egg each to account for the high mortality rate during the incubation period. After the application of sterile filter paper discs and 24 hours of incubation, only 48 (85.71\%) survived with a mortality of $14.29 \%$ which corresponds to 8 duck eggs.

Duck embryo in ovo chorioallantoic membrane (CAM) assay analysis

Figure 1 shows the sample images from the analysis of the average vessel diameter $\left(D_{V}\right)$. Each image was binarized (converted to black and white) and the percent area (\%area) was recorded which accounts for the vessel area density $\left(\rho_{A}\right)$. Then, the image was skeletonized where the percent area $(\%$ area) was also recorded which accounts, this time, for the vessel length density $\left(\rho_{\mathrm{L}}\right)$.

In Figure 2 the analysis of the total length $\left(\mathrm{L}_{\mathrm{T}}\right)$ and the color threshold of the images were adjusted to emphasize the blood vessels. The images were then subjected to human umbilical vein endothelial cells (HUVEC) phase contrast analyzer.
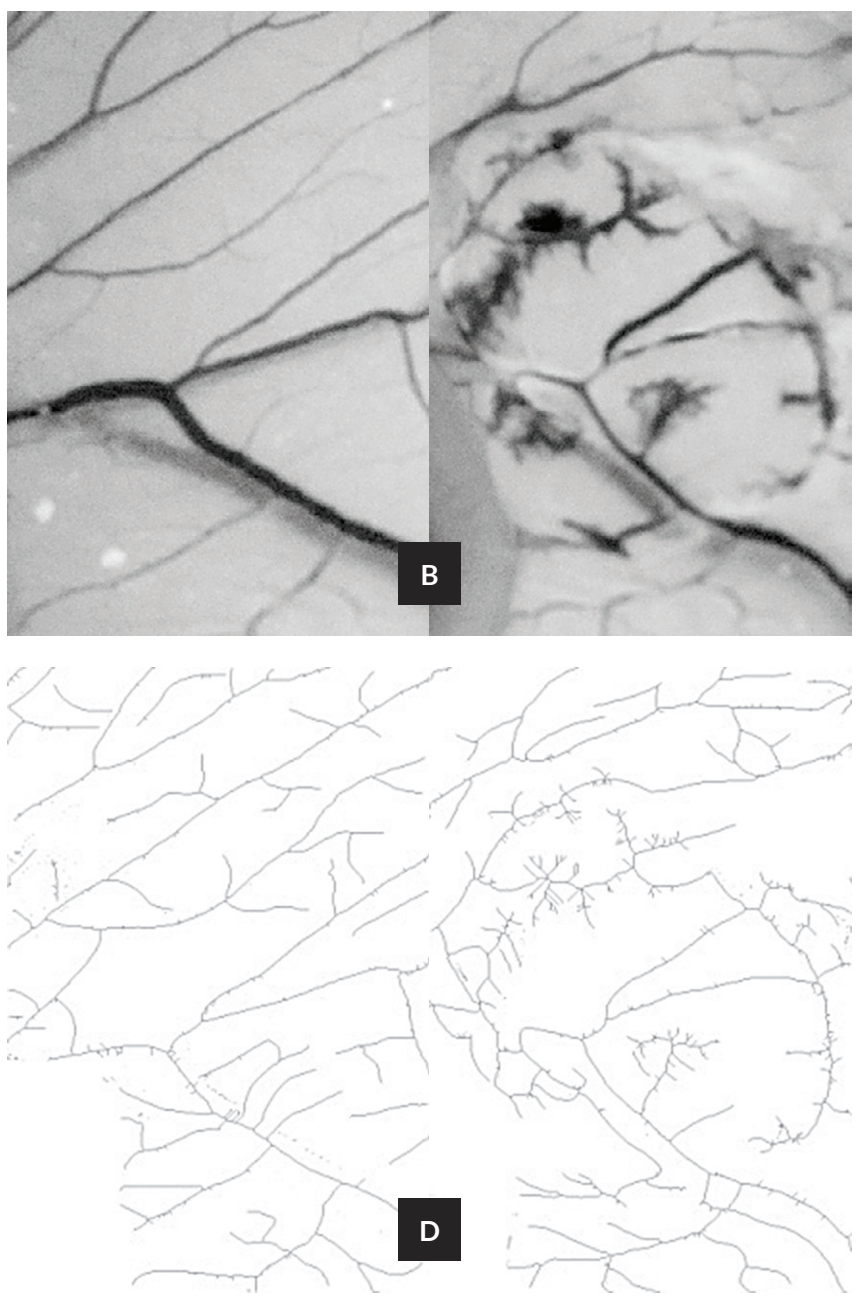

Figure 1. Sample images for the ImageJ software analysis of average vessel diameter $\left(D_{v}\right)$ (butanol fraction trial 1$)$; (A) raw images, (B) images with green channel selected, (C) binarized images, (D) skeletonized images; (left) pre-test observation, (right) post-test observation. 


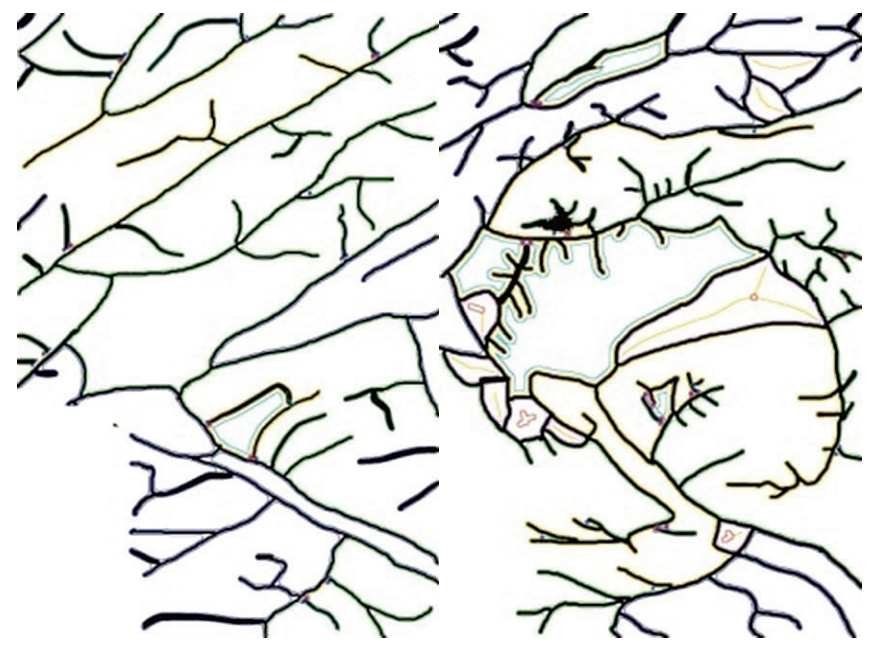

Figure 2. Sample images for the ImageJ software analysis of total length $\left(\mathrm{L}_{T}\right)$ (butanol fraction trial 1); (a) pre-test observation, (b) post-test observation.

Table 3. Summary of the mean percent inhibition of the treatment groups

\begin{tabular}{lcc}
\multirow{2}{*}{\multicolumn{1}{c}{ Treatment Group }} & \multicolumn{2}{c}{ Mean \%lnhibition \pm SEM } \\
\cline { 2 - 3 } & $\begin{array}{c}\text { Average Vessel } \\
\text { Diameter }\left(\mathrm{D}_{\mathrm{V}}\right)\end{array}$ & Total Length $\left(\mathrm{L}_{\mathrm{T}}\right)$ \\
\hline Positive control & $191.76 \pm 32.52$ & $33.09 \pm 14.22$ \\
Crude methanolic extract & $304.62 \pm 132.73$ & $33.55 \pm 1.74$ \\
Aqueous fraction & $-117.41 \pm 191.82$ & $28.25 \pm 22.80$ \\
Methanol:waterfraction & $-51.97 \pm 148.76$ & $-26.07 \pm 18.02$ \\
Butanol fraction & $417.30 \pm 300.83$ & $44.21 \pm 8.11$ \\
Dichloromethane fraction & $-60.95 \pm 148.33$ & $-32.60 \pm 12.45$ \\
Hexane fraction & $-718.18 \pm 68.39$ & $-3.88 \pm 19.63$ \\
\hline
\end{tabular}

The percent inhibition of each trial for both parameters, average vessel diameter $\left(\mathrm{D}_{\mathrm{V}}\right)$, and total length $\left(\mathrm{L}_{\mathrm{T}}\right)$, was then computed using Equations 1, 3, and 4. The tabular and graphical summaries for the mean percent inhibition \pm SEM of all the treatments groups are shown in Table 3 and Figure 3, respectively.

\section{Statistical analysis}

The mean percent inhibitions for parameters $\mathrm{D}_{\mathrm{V}}$ and $\mathrm{L}_{\mathrm{T}}$ were further analyzed using the statistical software Stata/ MP-Parallel Edition 13.0. All statistical tests were done at the 0.05 level of significance. Bartlett's test for equal

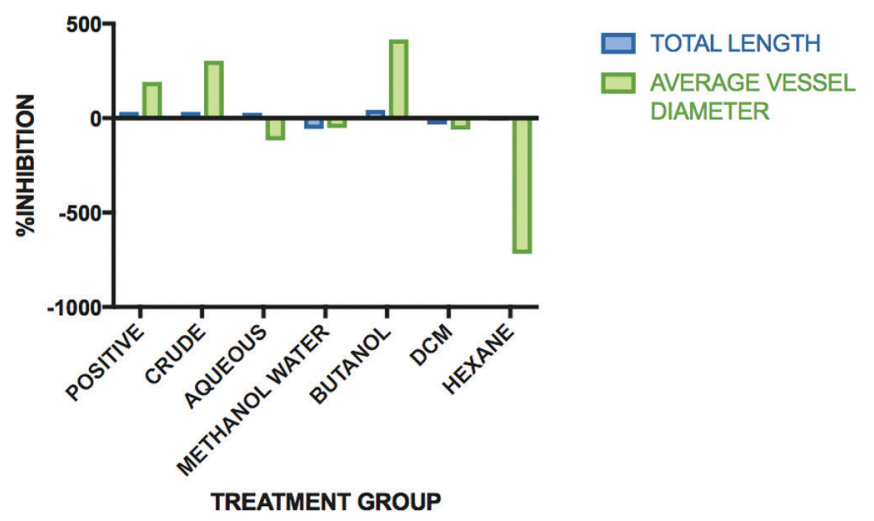

Figure 3. Graph of the percent inhibitions of the treatment groups for average vessel diameter $\left(D_{\vee}\right)$ and total length $\left(\mathrm{L}_{\mathrm{T}}\right)$.

variances showed that there was no sufficient evidence that the variances among the treatment groups were heterogenous both for the average vessel diameter $(p=0.270)$ and total length $(p=0.067)$. The significant differences of the percent inhibition between the positive control and the treatment groups were determined using one-way ANOVA Dunnett's post hoc test; likewise, the significant difference between the crude methanolic extract and butanol fraction was also determined using Tukey's HSD post hoc test $\left(\mathrm{D}_{\mathrm{V}}\right.$ $p=0.999 ; \mathrm{L}_{\mathrm{T}} p=1.000$ ). The results for both the Shapiro-Wilk test and Dunnett's posthoc test are shown in Table 4.

\section{Biochemical screening}

Table 5 shows the results of biochemical screening.

\section{DISCUSSION}

Methanol is the extraction solvent of choice for most studies involving marine natural products, thus used in the extraction of Telescopium telescopium in the study. A series of solvents of increasing polarity through modified Kupchan partitioning was employed. Most non-polar compounds such as fats are expected to solubilize with the hexane fraction; on the other hand, polar compounds such as inorganic salts are expected to be found in the aqueous fraction. Modified Kupchan partitioning allows most of the fats to go with the n-hexane fraction, while inorganic

Table 4. Shapiro-wilk test and Dunnett's post hoc test p-values of the treatment groups

\begin{tabular}{|c|c|c|c|c|}
\hline \multirow[b]{2}{*}{ Treatment group } & \multicolumn{2}{|c|}{ Shapiro-wilk test $p$-value $(a=0.05)$} & \multicolumn{2}{|c|}{ Dunnett'spost hoc test $p$-value $(\alpha=0.05)$} \\
\hline & $\begin{array}{l}\text { Average vessel diameter }\left(D_{v}\right) \\
(\mathrm{mm})\end{array}$ & $\begin{array}{l}\text { Total length }\left(\mathrm{L}_{\mathrm{T}}\right) \\
\text { (pixel) }\end{array}$ & $\begin{array}{l}\text { Average vessel diameter }\left(D_{\vee}\right) \\
(\mathrm{mm})\end{array}$ & $\begin{array}{l}\text { Total length }\left(\mathrm{L}_{\mathrm{T}}\right) \\
\text { (pixel) }\end{array}$ \\
\hline Positive control & 0.08664 & 0.76187 & - & - \\
\hline Crude methanolic extract & 0.37098 & 0.20979 & 0.992 & 1.000 \\
\hline Aqueous fraction & 0.81612 & 0.11088 & 0.619 & 1.000 \\
\hline Methanol:water fraction & 0.56640 & 0.85522 & 0.798 & 0.226 \\
\hline Butanol fraction & 0.01576 & 0.13042 & 0.843 & 0.997 \\
\hline Dichloromethane fraction & 0.88687 & 0.25342 & 0.775 & 0.156 \\
\hline Hexane fraction & 0.84480 & 0.30955 & 0.008 & 0.639 \\
\hline
\end{tabular}


Table 5. Summary of the results from biochemical screening

\begin{tabular}{|c|c|c|c|c|}
\hline \multirow{2}{*}{\multicolumn{2}{|c|}{ Biochemical screening test }} & \multirow{2}{*}{ Theoretical result } & Crude methanolic & Butanol fraction \\
\hline & & & \multicolumn{2}{|c|}{ Actual result } \\
\hline \multirow{2}{*}{ Carbohydrates } & Fehling & Red precipitate & $(+)$ & $(+)$ \\
\hline & Molisch & Red or dull violet color at the interphase of the layers & $(+)$ & $(+)$ \\
\hline Proteins & Biuret & Violet solution & Orange-brown solution & Gray solution \\
\hline \multirow{2}{*}{ Sterols } & Liebermann-Burchard & Red ring at the junction of the layers & $(+)$ & $(+)$ \\
\hline & Salkowski & Red solution (upon standing) & $(+)$ & $(+)$ \\
\hline \multirow{4}{*}{ Alkaloids } & Dragendorff & Yellow to orange precipitate & Yellow solution & Red-orange solution \\
\hline & Valser & White precipitate & Yellow solution & Light yellow solution \\
\hline & Mayer & White precipitate & Yellow solution & Light yellow solution \\
\hline & Wagner & Reddish brown precipitate & Red-brown solution & Red-brown solution \\
\hline
\end{tabular}

salts will go with the aqueous one, thus certain degree of fractionation is achieved. ${ }^{11}$

The percent yields in extraction exhibited that most of the composition of the methanolic extract of Telescopium telescopium species is polar in nature. It can also be supported from the fact that cholesterols, phospholipids, and triglycerides found in marine invertebrates specifically gastropods such as Telescopium telescopium are known to be polar compounds. ${ }^{12}$

The success of the conduct of the CAM assay relied on considerations such as proper procurement, transport, acclimatization, and handling of the eggs, minimizing mortality rate. Six-day old eggs were used since during this time of chick embryo development, the blood vessel system of the CAM is highly angiogenic, that is, undergoing maturation through a constant generation of new blood vessels as well as establishment of new blood vessel anastomoses; therefore, the developing CAM vasculature is highly responsive to antiangiogenic factors. This feature renders the chick embryo test organisms as the appropriate experimental validation of antiangiogenic compounds. ${ }^{13}$

The degrees of inhibition for the average vessel diameter $\left(D_{V}\right)$ across trials were significantly different among each other. As new blood vessels grow, vessel systems become more compact and smaller to compensate for the lack of space for the new vessels, thereby resulting in decrease of average vessel diameter. Variability like such, however, did not make results invalid since the growth and development of each embryo is predetermined by their genes. Disregarding other factors that may influence its development, the size of the embryo and the rate by which its blood vessels proliferate are all based on its parentage. ${ }^{14}$ To reduce other variability, all the fertilized eggs came from the same farm and were of the same age.

The trends observed with the percent inhibition of the average vessel diameter $\left(D_{V}\right)$ and total length $\left(L_{T}\right)$ were almost similar. In both parameters, the crude methanolic extract indicate a decrease in vascularization. In a 2014 study by Gupta et al., the methanolic extracts of Telescopium telescopium, together with Bursa crumena, Meretrix meretrix, and Meretix casta, also exhibited noticeable antiangiogenic activity in the CAM assay. ${ }^{2}$

This suggests that a synergistic action causing antiangiogenesis may be present in the crude extract.
Meanwhile, the fraction with the highest percent inhibition for both parameters is butanol fraction, implying that the antiangiogenic compound of interest is of similar polarity with butanol.

The vessel diameter growth involved in tube formation occurs during the early stages of development as compared to the total length, which significantly starts to increase only when sprouting begins, with a peak between Day 8 and Day 10. Sprouting angiogenesis is characterized by sprouts composed of endothelial cells, which usually grow toward an angiogenic stimulus such as vascular endothelial growth factor A (VEGF-A), therefore adding blood vessels to portions of tissues previously devoid of blood vessels. ${ }^{15}$

In literature, the capillary plexus is formed and grows rapidly from Day 4 to Day 5 via vasculogenesis and sprouting angiogenesis, but the proliferation decreases after Day 11 . The processes involved in the capillary plexus formation are at first sprouting, but very soon intussusceptive microvascular growth is the main process which leads to increased density and complexity. ${ }^{16}$ It is then expected for the average vessel diameter values to be more sensitive since the assay is done on younger eggs. The response of the CAM to angiogenic stimuli is relatively rapid and most assays require only 3 to 5 days. ${ }^{17}$ The high percent inhibition values seen for the average vessel diameter, then, supports that the antiangiogenic compounds of interest works effectively as early as the young stages of the development of blood vessels.

As for positive control of the assay, quercetin was used, which resulted to positive percent inhibition both for the average vessel diameter $(191.76 \pm 32.52 \mathrm{~mm})$ and total length (33.09 \pm 14.22 pixels). Rat aortic ring assay (ex vivo), chicken egg chorioallantoic membrane assay (CAM) (in vivo), and matrigel plug assay (in vitro) have shown quercetin, at nontoxic concentrations, to significantly inhibit microvessel sprouting as well as proliferation, migration, invasion, and tube formation of endothelial cells, which are key events in the process of angiogenesis. ${ }^{18}$

In both parameters, the crude methanolic extract and butanol fraction resulted to higher percent inhibitions than quercetin. However, there was no sufficient evidence that the crude methanolic extract $\left(\mathrm{D}_{\mathrm{V}} \mathrm{p}=0.992 ; \mathrm{L}_{\mathrm{T}} \mathrm{p}=1.000\right)$ nor the butanol fraction $\left(\mathrm{D}_{\mathrm{V}} p=0.843 ; \mathrm{L}_{\mathrm{T}} p=0.997\right)$ had higher antiangiogenic activities than quercetin, suggesting that 
the crude methanolic extract and butane fraction were just equally comparable to the positive control. Between the crude methanolic extract and butanol fraction, there was also no sufficient evidence that their antiangiogenic activity was different $\left(\mathrm{D}_{\mathrm{V}} p=0.999 ; \mathrm{L}_{\mathrm{T}} p=1.000\right)$. It only suggests that the butanol fraction was able to fraction out majority, if not all, of the antiangiogenic compound of interest present in the crude extract.

The high percent yield of the butanolic fraction from the modified Kupchan partitioning and its resulting high percent inhibition is noted from the result of the study. It can be indicated that the compound responsible for the antiangiogenic activity of T. telescopium was polar in nature and is of large component of the species. The methanolic extract had the second highest percent inhibition following the butanolic fraction. Supporting this result is a study conducted by Gupta et. al. which screened twenty two marine invertebrate extracts from the phylum Mollusca, including T. telescopium. Among all the extracts used, the methanolic extract had the most noticeable antiangiogenic activity in their study. ${ }^{2}$

The crude extract and butanol fraction tested positive for the presence of both sterols and carbohydrates. These compounds may be assumed responsible for the antiangiogenic activity of the T. telescopium. Generally, carbohydrates are readily soluble in water and therefore present in the aqueous fraction. However, based from the results of the study, aqueous fraction resulted to a negative inhibition for total length. In addition, the carbohydrate composition of $T$. telescopium is only about of $0.8 \%$ of its total biochemical components. Therefore, it can be assumed that carbohydrates may have no contribution to the significant antiangiogenic activity of the animal sample. ${ }^{10}$

Sterols, on the other hand, a major constituent in marine organisms including mollusks, are found to suppress the growth of blood vessel in cancer cells. Thus, the positive results for both Liebermann-Burchard and Salkowski tests support the assumption that the compound responsible for the antiangiogenic activity of Telescopium telescopium is a sterol. This is further supported by the fact that the basic types of lipids found to occur in mollusks include sterols, phospholipids, triacylglycerols, glycolipids to a lesser extent, and fatty acids. Major sterols occurring in gastropods include cholesterol, 5,7-sterols, brassicasterol and $\beta$-sitosterol in different quantities. ${ }^{19}$

Sterols, or steroidal alcohols, being amphipathic lipids, have both a polar head group and a non-polar sterol tail. Since partly polar, the sterol compounds of the Telescopium telescopium were extracted in the aqueous layer at the initial part of the fractionation. When the aqueous layer was further extracted with butanol, sterols, which are partly non-polar in nature, were fractioned out due to the fact that butanol is less polar as compared to distilled water and has at least minimum non-polar polarity. In addition, the solubility of sterols in alcoholic solvents increases with the chain length of the hydrocarbon moiety of the alcohol so these compounds become more soluble in ethanol and completely soluble in n-butanol. ${ }^{20}$

\section{CONCLUSION}

Upon quantifying the percent inhibitions using two parameters - average vessel diameter $\left(\mathrm{D}_{\mathrm{V}}\right)$ and total length $\left(\mathrm{L}_{\mathrm{T}}\right)$ - in ImageJ software, both the crude methanolic extract and butanol fraction were found to have antiangiogenic activity as indicated by their positive percent inhibition values. However, despite having greater percent inhibition values than positive control, the antiangiogenic activity of the crude methanolic extract and the butanol fraction has no significant difference from the standard quercetin. The biochemical screening of both the butanol fraction and crude methanolic extract showed the presence of carbohydrates and sterols. However, carbohydrates present in aqueous fraction, showed no significant antiangiogenic activity. Moreover, carbohydrates was found to be low in Telescopium telescopium. On the other hand, sterols assumed to be present in butanol exhibited the highest antiangiogenic activity among the fractions. Sterols, therefore are assumed as the biochemical class of the compound that greatly contributed to the antiangiogenic activity of Telescopium telescopium, conferring its potential as an anticancer agent.

\section{Acknowledgments}

This study was supported by the National Institutes of Health, University of the Philippines Manila. We would like to express our gratitude to the faculty and staff of College of Pharmacy, University of the Philippines Manila, particularly to Assistant Professor Levi Letlet Larcia and to the staff of the Institute of Pharmaceutical Sciences for their technical support.

\section{Statement of Authorship}

All authors have approved the final version submitted.

\section{Author Disclosure}

All authors have declared no conflict of interest.

\section{Funding Source}

This paper was funded by the National Institutes of Health, University of the Philippines Manila.

\section{REFERENCES}

1. Aguila SR,Tan MA,Villaflores OB.The antiangiogenic and antibacterial effect of Tinomiscium philippinenses Miers. (Menispermaceae) leaf extract. Journal of Coastal Life Medicine.2016;4(1):61-8. https://doi. org/10.12980/jclm.4.2016j5-145.

2. Gupta P, Arumugam M, Azad R, et. al. Screening of antiangiogenic potential of twenty-two marine invertebrate extracts of phylum mollusca from south east coast of India. Asian Pacific Journal of Tropical biomedicine. 2014; 4 (1): S129-38. https://doi.org/10.12980/ APJTB.4.2014C701. 
3. Folkman J. Angiogenesis in cancer, vascular, rheumatoid and other disease. Nature Medicine.1995;1(1):27-30.

4. Polverini PJ. The pathophysiology of angiogenesis. Critical review in oral biology and medicine: an official publication of the American Association of Oral Biologists.1995;6(3):230-47.

5. Subhasis R, Uttan D, Debaki G. Potential future applications of spermatheca extract from the marine snail Telescopium telescopium. Turkish Journal of Veterinary Animal Sciences.2010;34(6):533-40.

6. Mayer A, Glaser K, Cuevas C, et al. The odyssey of marine pharmaceuticals: a current pipeline perspective. Trends Pharmacol Sci. 2010;31(6):255-65. https://doi.org/10.1016/j.tips.2010.02.005.

7. Samanta SK, Adhikari D, Karmakar S, et. al. Pharmacological and biochemical studies on Telescopium telescopium marine mollusk from the mangrove regions. Oriental Pharmacy and Experimental Medicine. 2008;8(4):386-94. DOI : 10.3742/OPEM.2008.8.4.386.

8. Sys GM, Lapeire L, Stevens N, et. al. The in ovo CAM assay as a xenograft model for sarcoma. [Online]. 2013 [cited 2016 October] Available from https://www.ncbi.nlm.nih.gov/pubmed/?term=The+in+ ovo+CAM+assay+as+a+xenograft+model+for+sarcoma.

9. Galia ML, Galia JD. Antiangiogenic activity of TinosporarumphiiBoerl (makabuhay) leaf and stem extracts. International Research Journal of Biological Sciences. 2016;5(1):54-9.

10. Chakravarty M, Dogiparti A, Sudha S, Ganesh PRC. Biochemical composition of three Potamidid snails - Telescopium telescopium, Cerithidea cingulate and C. obtuse of Tekali Creek (Bhavanapadu mangroves), Andhra Pradesh, India. [Online]. 2015 [cited 2017 May] Available from http://www.imedpub.com/articles/biochemicalcomposition-of-three-potamidid-snailstelescopiumtelescopiumcerithidea-cingulate-and-c-obtusa-of-tekkali-creekbhavanap.pdf .

11. Sarker S, Latif Z, Gray A. Methods in biotechnology: natural products isolation, 2nd ed. Totowa NJ, J. Med. Chem., 2006, 49 (8), 2666. DOI: 10.1021/jm0680068.

12. Rakshit S, Bhattacharyya D, Misra K. Distribution of major lipids and fatty acids of the estuarine gastropod mollusc Telescopium telescopium. Folia Biologica (Krakow). 1997;45(1-2):83-6.
13. Deryugina E, Quigley J. Chapter 2: Chick embryo chorioallantoic membrane models to quantify angiogenesis induced by inflammatory and tumor cells purified effector molecules. [Online]. 2008 [cited 2016 October] Available from https://www.ncbi.nlm.nih.gov/pmc/articles/ PMC2699944/.

14. Iranga F, Caimbon L, Aterrado C, Litan III S, Claridad N, Garcia M. Heat stress as an angiogenic factor in duck embryo. [Online]. n.d. [cited 2016 October] Available from http://www.academia.edu/9845341/ HEAT_STRESS_AS_AN_ANGIOGENIC_FACTOR_IN_ DUCK_EMBRYO.

15. Adair T, Montani J.P. Angiogenesis. [Online]. 2010. [cited 2016 October]. Available from https://www.ncbi.nlm.nih.gov/books/ NBK53238/.

16. Verhoelst E. Structural analysis of the angiogenesis in the chicken chorioallantoicmembrane. [Online]. 2011. [cited 2016 October] Available from https://lirias.k $\mu$ Leuven.be/bitstream/ 123456789/293316/1/.

17. Yuan, YJ, Xu K, Wu W, Luo Q, Yu JL. Application of the chick chorioallantoic membrane in neurosurgery disease. Int J Med Sci, 2014;11(12):1275-81.

18. Pratheeshkumar, P., Budhraja A., Son, Y.O, et al. Quercetin inhibits angiogenesis mediated human prostate tumor growth by targeting VEGFR-2 Regulated AKT/mTOR/P70S6K Signaling Pathways [Online]. 2012. [cited 2016 October] Available from: http://journals. plos.org/plosone/article?id=10.1371/journal. pone.0047516. https:// doi.org/10.1371/journal.pone.0047516.

19. Voogt, PA. Lipid and sterol components and metabolism in Mollusca. In: Chemical Zoology, 1st ed. USA: Academic Press; 1972. pp.329-70.

20. Kurladze G, Ivanova L. Cell differentiation research developments. Nova Science Publishers Inc; 2008. pp. 146. 